\title{
A Study on Customer Satisfaction of Mobile Wallet Services Provided by Paytm
}

\author{
Saviour F \\ Research Scholar, Department of Commerce, Scott Christian College, Nagercoil, INDIA
}

Corresponding Author: itssaviour4u@gmail.com

\begin{abstract}
In today - world, smart phone has become an essential part of one's daily life. Mobile users can nowadays use their Smartphones to make money transactions or payments by using applications installed in the phone. There are several mobile wallets which provide these services. Mobile wallets are digital versions of traditional wallets that someone would carry in their pocket. They offer payment services through which the individuals/business can receive /send money via mobile devices. The present paper throws light upon the customer satisfaction level towards the ewallet services provided by paytm. It focusses on the services provided by Paytm wallet and its satisfaction level..
\end{abstract}

Keywords-- Customer Satisfaction, Paytm, Ewallet, Paytm Services, Customer Satisfaction of Ewallets

\section{INTRODUCTION}

An electronic device that allows an individual to make electronic commerce transactions is termed as a digital wallet. This can include purchasing items online using a Smartphone or with a computer to purchase something at a store. Digital wallet is also a system that securely Store users payment information and passwords for numerous payment methods and websites. Digital wallets can be used in conjugation with mobile payment systems that which allow the customers to pay for purchases with the help of their smart phones. They can also be used to store loyalty card information and digital coupons. It is also known as an e-wallet.

In India, where most of the population doesn't have credit and debit cards, the mobile phone is fast becoming a tool that act as a catalyst for digital payment solution. After E-commerce, the digital and wallet payments will be the next big wave. Paytm is one among them. Every human being is a consumer of different produces if there is no consumers, no business. Therefore, customer satisfaction is very important to every business concerns. Organizations that strive beyond minimum standards and exceed the expectations of their customers are likely to be leaders in their sector. Customers are recognized as key partners in shaping service development and assessing quality of service delivery. Here in this study, an attempt is made to study the customer satisfaction on various services provided by paytm.

\section{RESEARCH PROBLEM}

We are living in a world which is growing and developing without any limitations. In older ages, the banking started with merchant bankers, goldsmiths, money lenders and at that time there were no speedy transactions, no virtual banking, and no proper account maintenance. But now the banking field has achieved development up to a higher extent. Buying and selling, transfer of money, balance enquiry, changing the address, bill payment are done through internet and day by day it is increasing and also the e-banking offers a wide variety of services.

Paytm is an e-wallet that is helping in money transactions without having solid money and also offering safety to customer's transactions. At present, especially in India there is a growing opportunity for mobile wallet business. The main attractions of these mobile wallets are making fast and quick transactions, time saving, less costly, easy to access etc. Besides these advantages, there are some limitations on paytm such as insecurity, limitations on fund transfer, non-availability of auction facility etc. Due to these facts a comprehensive study is required to study the customer satisfaction of mobile wallet services provided by paytm. The purpose of this research is to study the satisfaction level of customers towards paytm services and know the most dissatisfied areas of services.

\section{SIGNIFICANCE OF STUDY}

From the ancient times banking plays a vital role in the development of nation as well as the individual. For the stable economic condition, banking helps to a higher extent. Nowadays the lifestyle of the people is getting too busy and therefore significance of ebanking are increasing day by day. They have no time to visit banks for the purpose of depositing or accepting cash, as well as for the other services provided by the bank. E-wallet services offer a lot of advantages to the common people that they can pay bills, and can take and give cash at any time anywhere without visiting a bank. These services help to save their money and also can be done with a good form of security. This will helps customers to engage in their own works and avoids additional expenses like travelling cost etc. Paytm is an ewallet software which can be used for the purpose of paying mobile bills, Electricity bills, and insurance and 
also for e-business and also pre booking of bus, car and bike, hotel, movies etc...It also deals with exclusive discount deals to satisfy and attract their customers. This research is important to study the satisfaction level of customers towards the services of Paytm.

\section{OBJECTIVES THE STUDY}

The primary objective of the study is "to study the satisfaction level among the Paytm users". Secondary objectives are:

1. To identify the most prominent area of dissatisfaction.

2. To study the factors that influence consumers in adoption of mobile wallets.

3. To find out suggestions to improve the services.

\section{RESEARCH METHODOLOGY}

The survey method is used as the main research tool for data collection. At first, the investigator approaches the user's paytm for gathering details. Then the prepared questionnaire is issued to user's to fill it. The direct interview method is also used for collecting primary data. After getting feedback from users, the data is evaluated properly and the results are interpreted.

\section{DATA ANALYSIS AND INTERPRETATION}

The data collected in the research were not simply because it contained unnecessary information and over or under emphasized facts. Therefore only relevant data were included in the analysis chapter. For better understanding, the collected data are simply tabulated and are also represented in the form of diagram and charts. Interpretation of the data is also given to share the meaningful information.

\section{FIGURE 1 : Age Group of Customers}

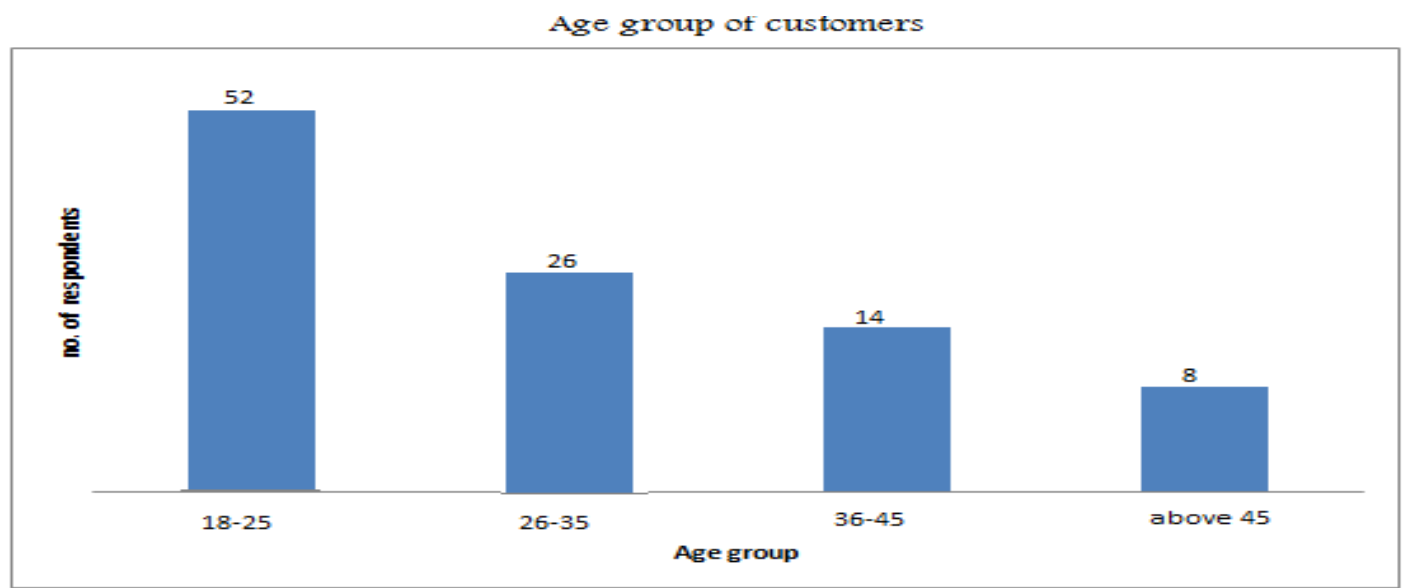

Source: Primary Data

\section{INTERPRETATION}

$26 \%$ of the customers belong to the age group of $26-35$. $52 \%$ covers $18-25$ age groups and $14 \%$ belongs to
$36-45$ age groups. Only $8 \%$ belongs to the age group of Above 45 .

FIGURE 2: Mobile recharging facility

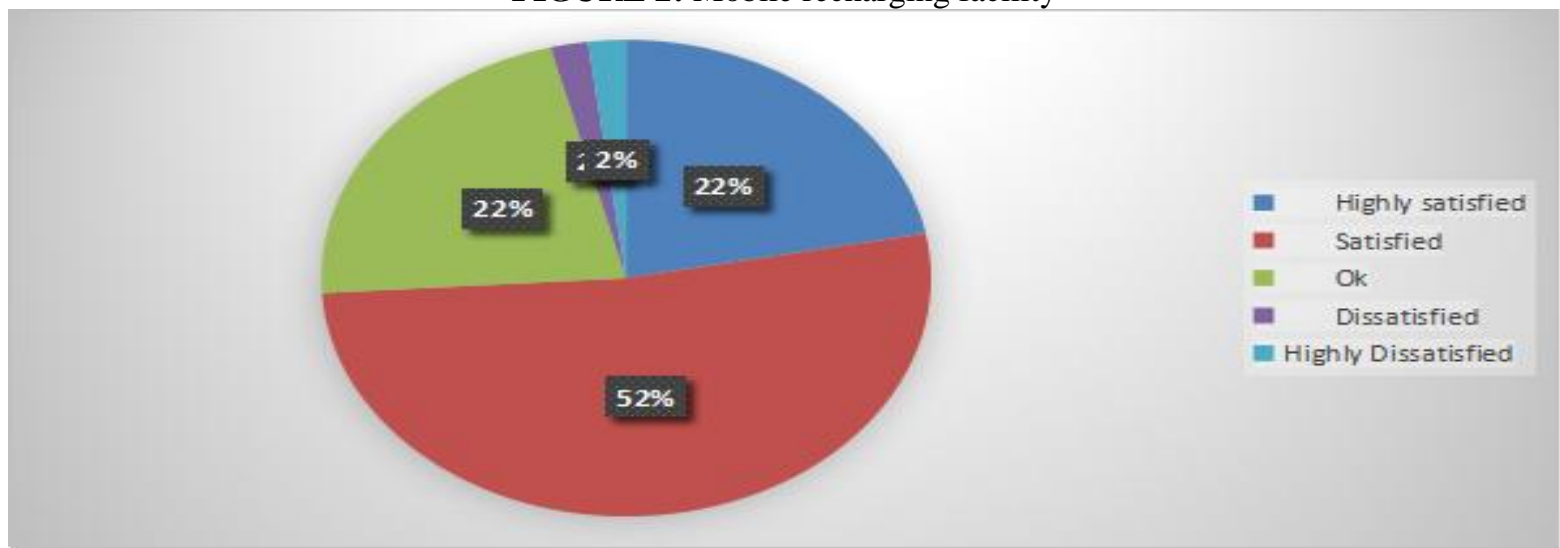

Source: Primary Data 


\section{INTERPRETATION}

It shows that $52 \%$ of respondents are satisfied with the mobile recharging facility of Paytm.
Only $22 \%$ are highly satisfied and $22 \%$ are OK to this facility.

FIGURE 3: Electricity bill payment facility

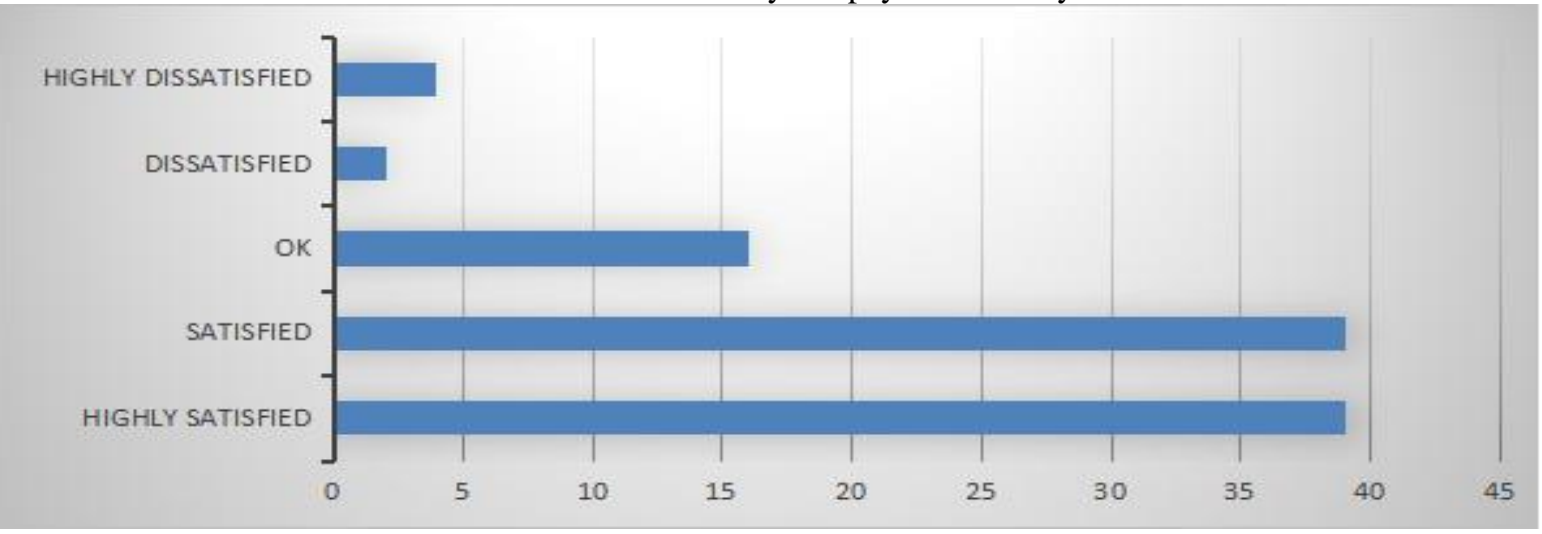

Source: Primary Data

INTERPRETATION

$39 \%$ are highly satisfied, $39 \%$ are satisfied, $16 \%$ are ok with the Service, $2 \%$ are dissatisfied and $4 \%$ are highly dissatisfied

FIGURE 4: Water bill payment facility

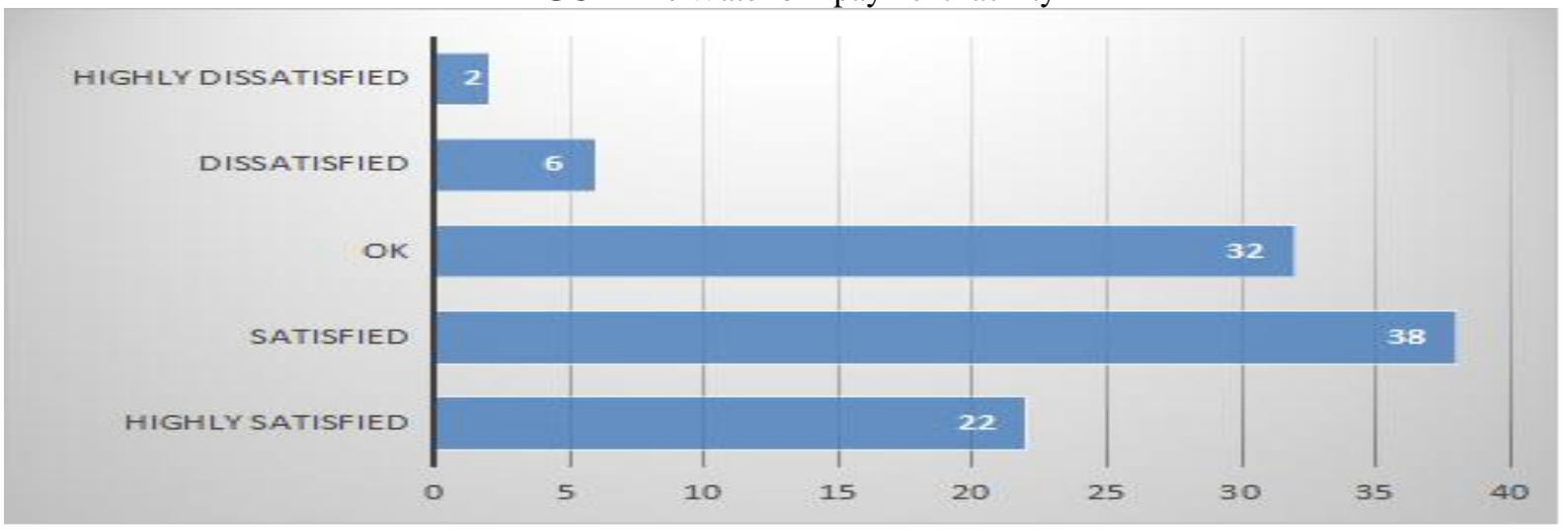

Source: Primary Data

INTERPRETATION

$22 \%$ are highly satisfied, $38 \%$ are satisfied, $32 \%$ are ok with the Service, $6 \%$ are dissatisfied and $2 \%$ are highly dissatisfied.

FIGURE 5: Insurance payment facility

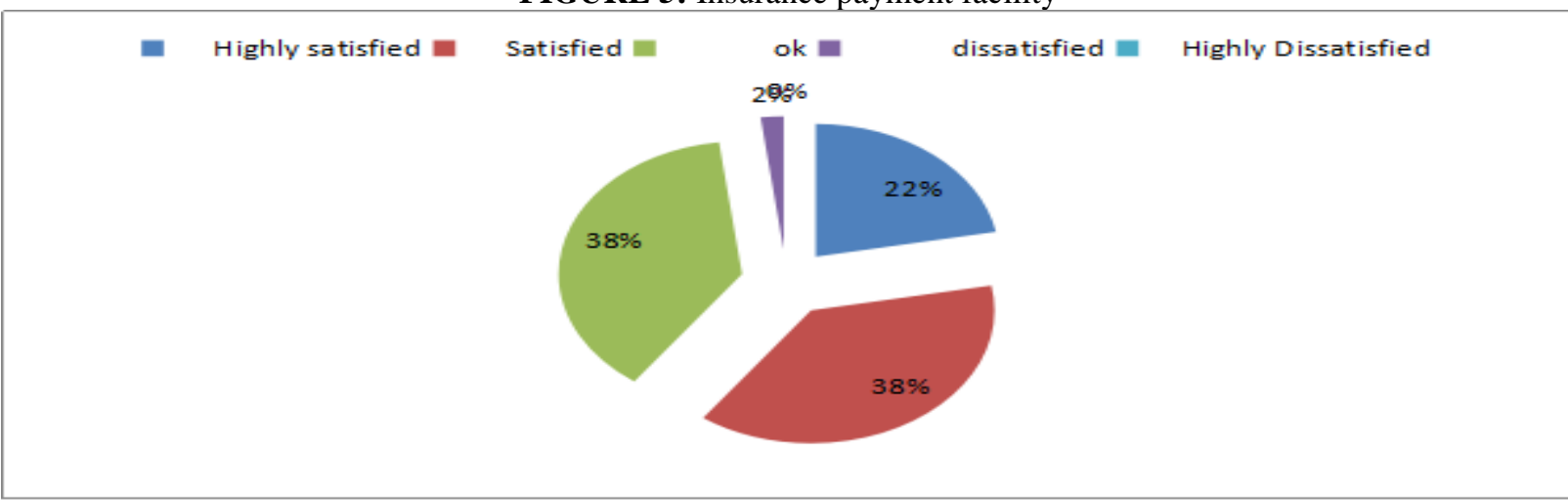

Source: Primary Data 


\section{INTERPRETATION}

$22 \%$ are highly satisfied, $38 \%$ are satisfied, 38 $\%$ are ok, $2 \%$ are dissatisfied

FIGURE 6: Software reliability

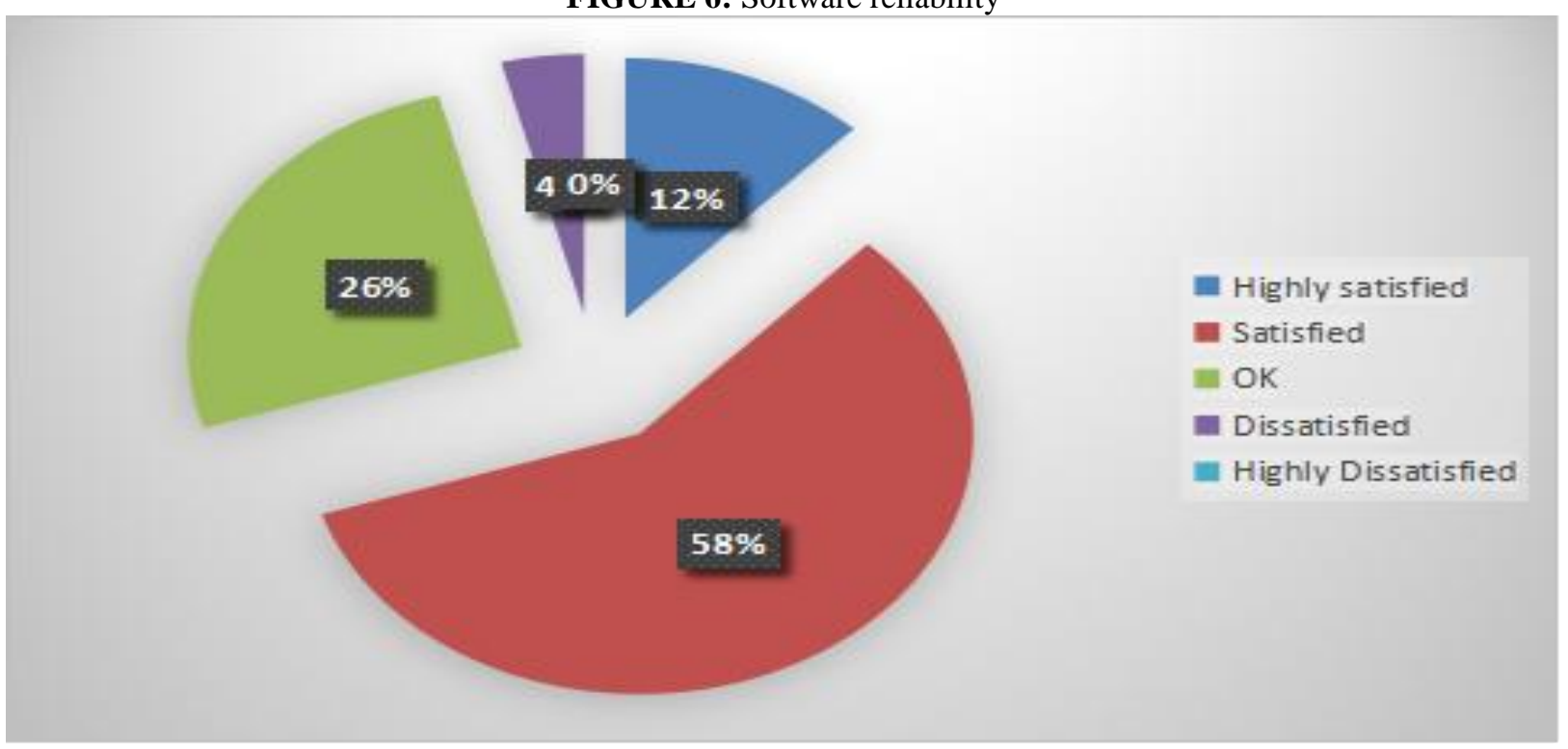

Source: Primary Data

INTERPRETATION

$12 \%$ are highly satisfied, $58 \%$ are satisfied, 26 $\%$ are ok and $4 \%$ are dissatisfied

FIGURE 7: Privacy Policy of Paytm

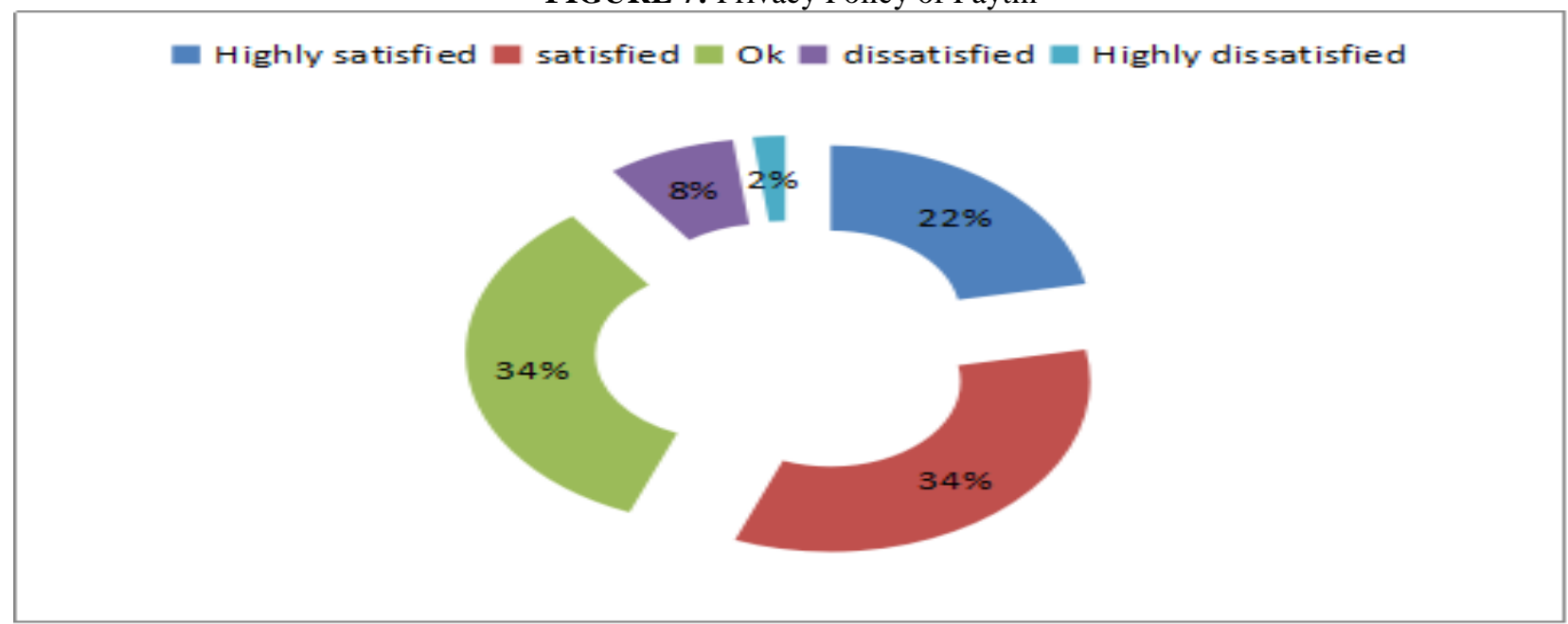

Source: Primary Data

INTERPRETATION
$22 \%$ are highly satisfied, $34 \%$ are satisfied, $34 \%$ are ok with the service, $8 \%$ are dissatisfied and only $2 \%$ are highly dissatisfied with the services. 
FIGURE 8: Bus Ticket booking facility

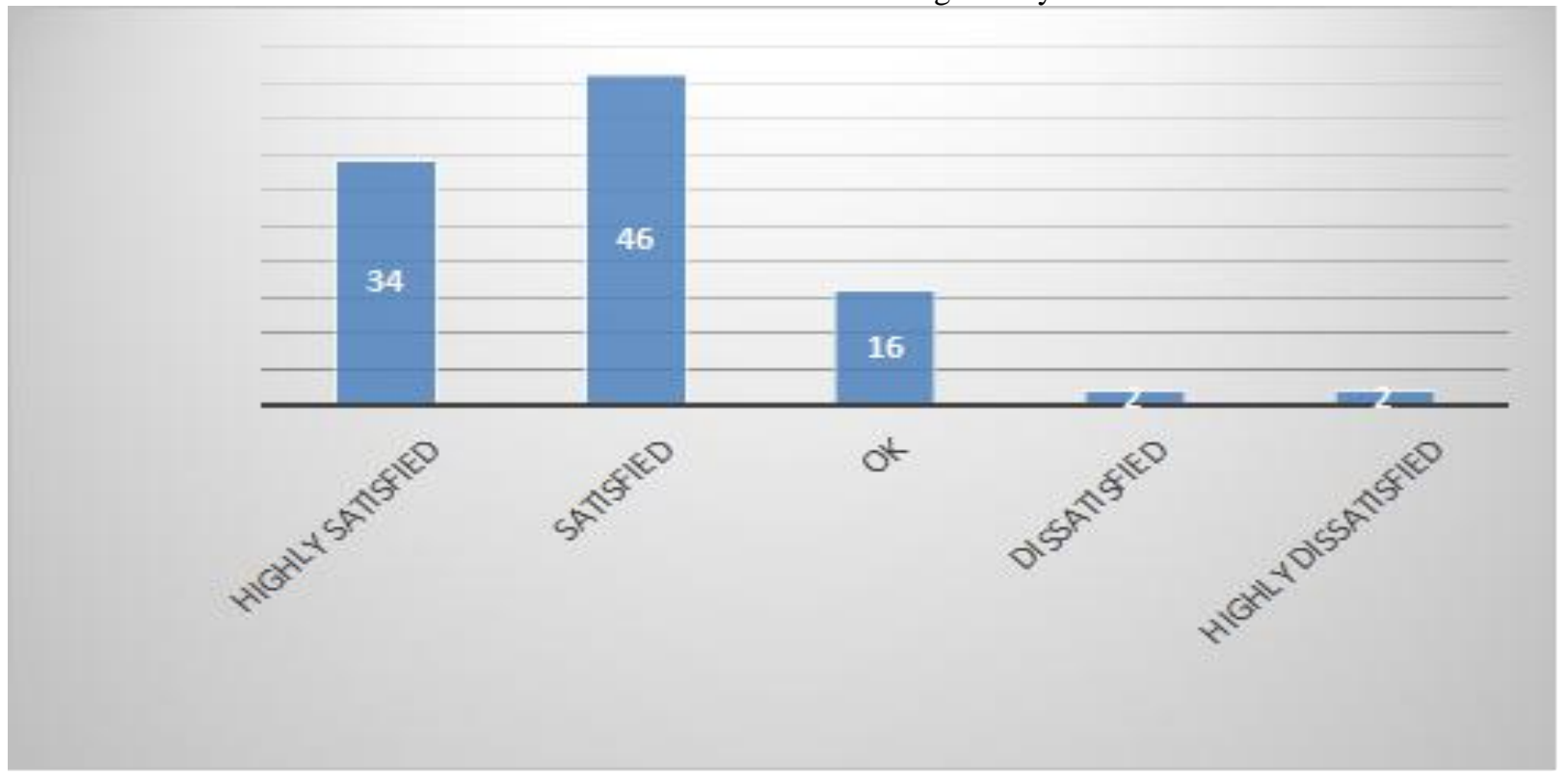

Source: Primary Data

INTERPRETATION

$34 \%$ are highly satisfied, $46 \%$ are satisfied, $16 \%$ are ok with the services, $2 \%$ are dissatisfied and $2 \%$ are highly dissatisfied.

FIGURE 9: Movie Ticket booking facility

Highly satisfied $\mathbf{n}$ Satisfied $\mathbf{m}$ OK $\mathbf{E}$ Dissatisfied $\mathbf{m}$ Highly Dissatisfied

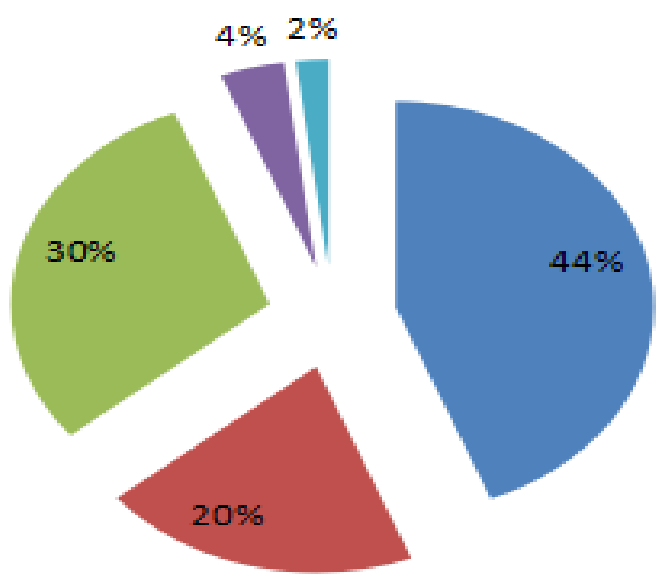

Source: Primary Data

INTERPRETATION

$44 \%$ are highly satisfied, $20 \%$ are satisfied, $30 \%$ are ok with the services, $4 \%$ are dissatisfied and $2 \%$ are highly dissatisfied. 
FIGURE 10: Hotel Room booking facility

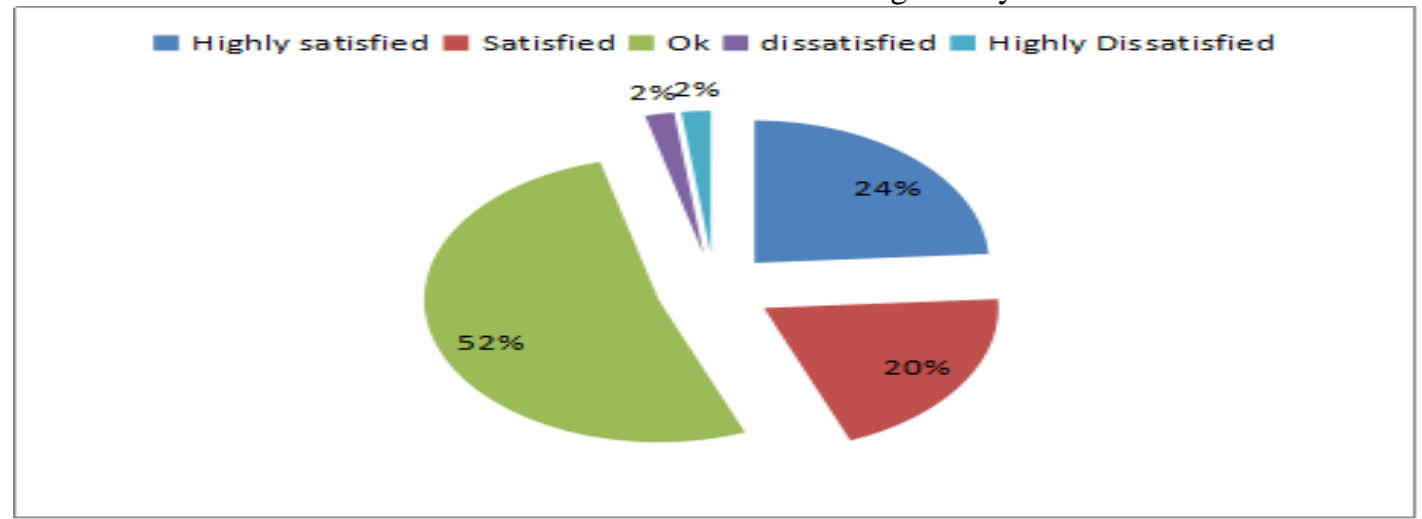

Source: Primary Data

\section{INTERPRETATION}

The diagram reveals that $24 \%$ are highly satisfied, $20 \%$ are satisfied and $50 \%$ are ok with the service.

FIGURE 11: Cash back offer

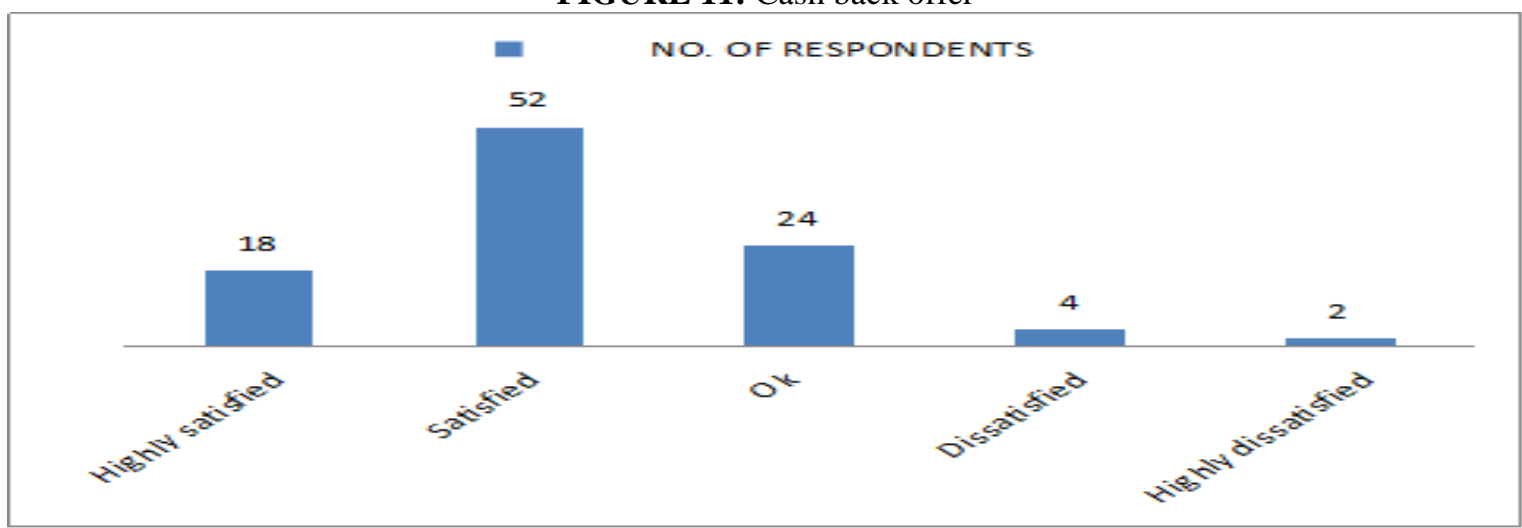

Source: Primary Data

\section{INTERPRETATION}

$18 \%$ are highly satisfied, $52 \%$ are satisfied, and $24 \%$ are ok with the service, $4 \%$ are dissatisfied and $2 \%$ are highly dissatisfied.

FIGURE 12: Respondents facing technical errors

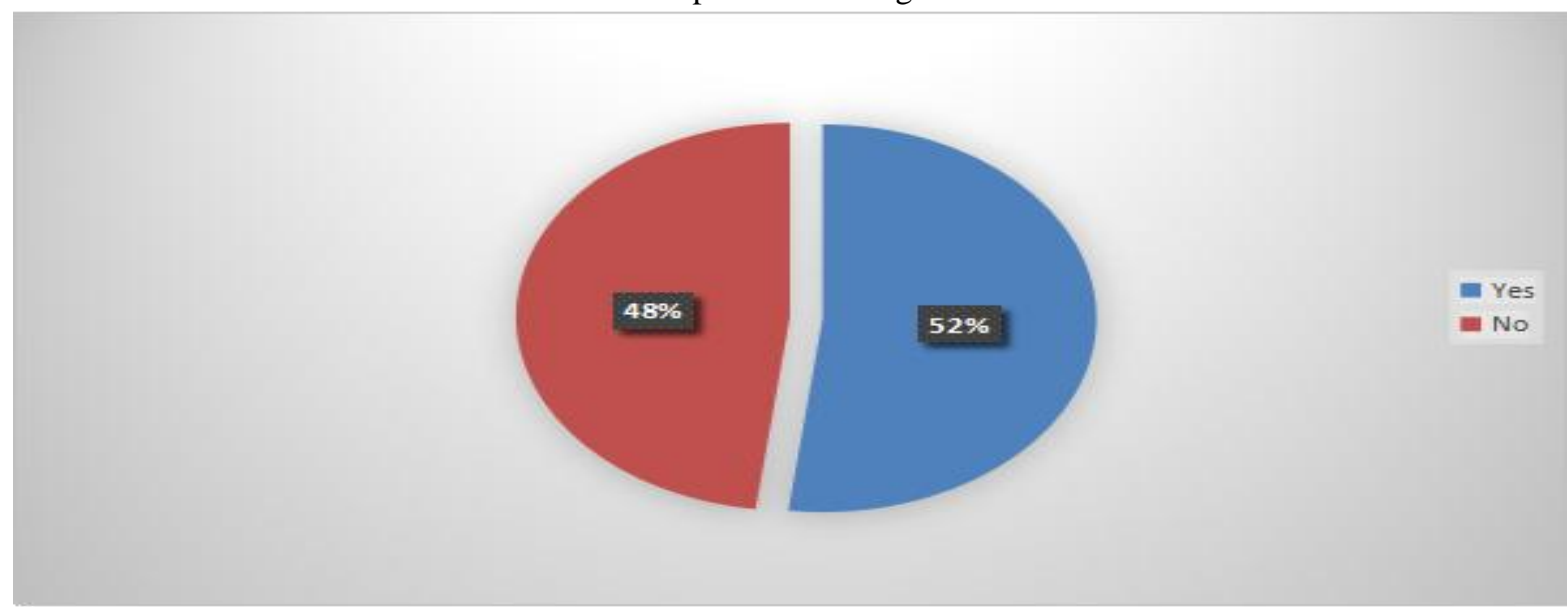




\section{INTERPRETATION}

FIGURE 13: Fund transfer facility

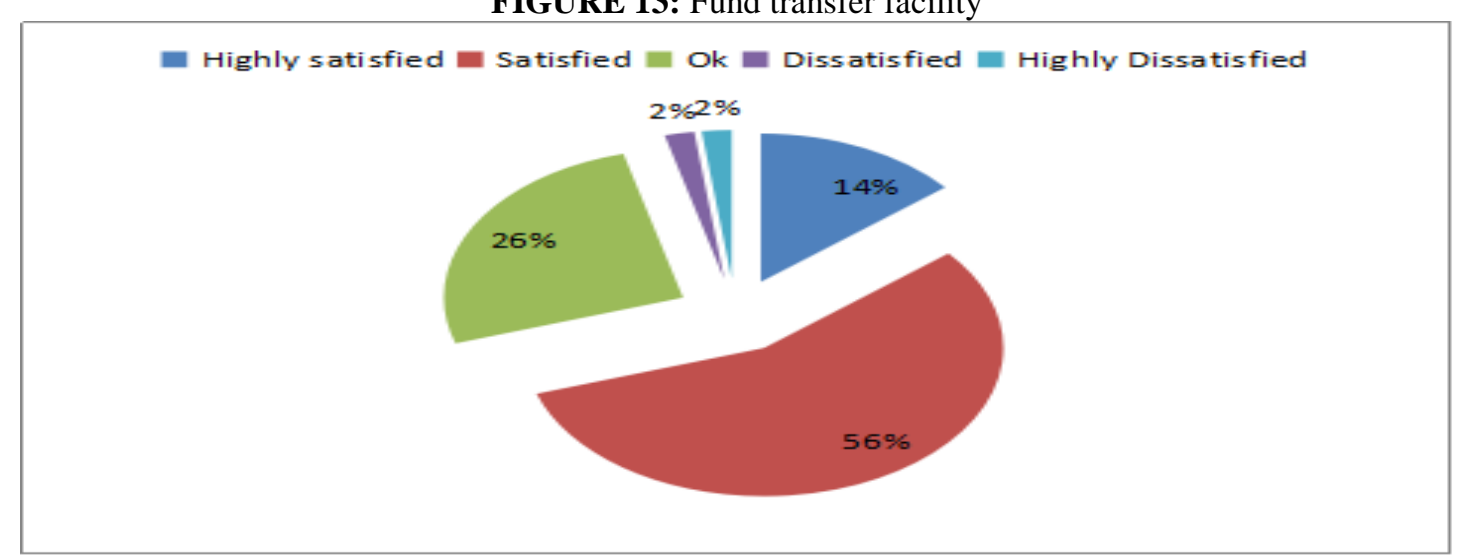

Source: Primary Data

\section{INTERPRETATION}

$14 \%$ are highly satisfied, $56 \%$ are satisfied, $26 \%$ are ok with the service, $2 \%$ are dissatisfied and $2 \%$ are highly dissatisfied

FIGURE 14 : Interest in shopping with Paytm

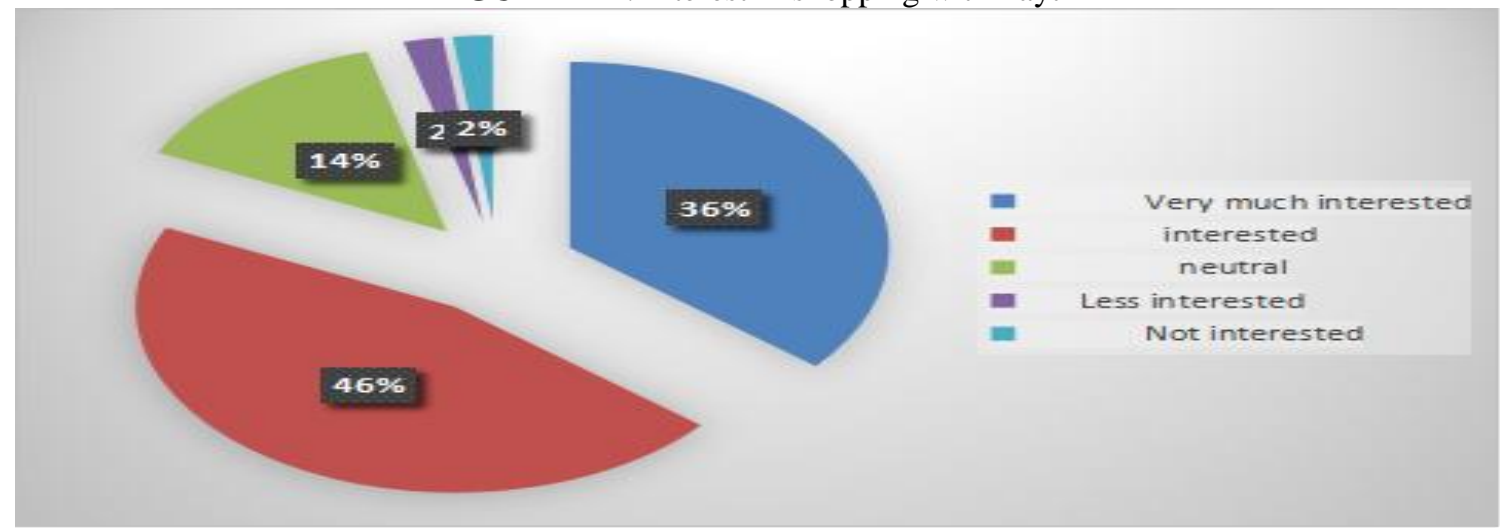

Source: Primary Data

\section{INTERPRETATION}

$36 \%$ are very much interested, $46 \%$ are interested, $14 \%$ are neutral, $2 \%$ are less interested and $2 \%$ are not interested.

FIGURE 15: Overall service satisfaction

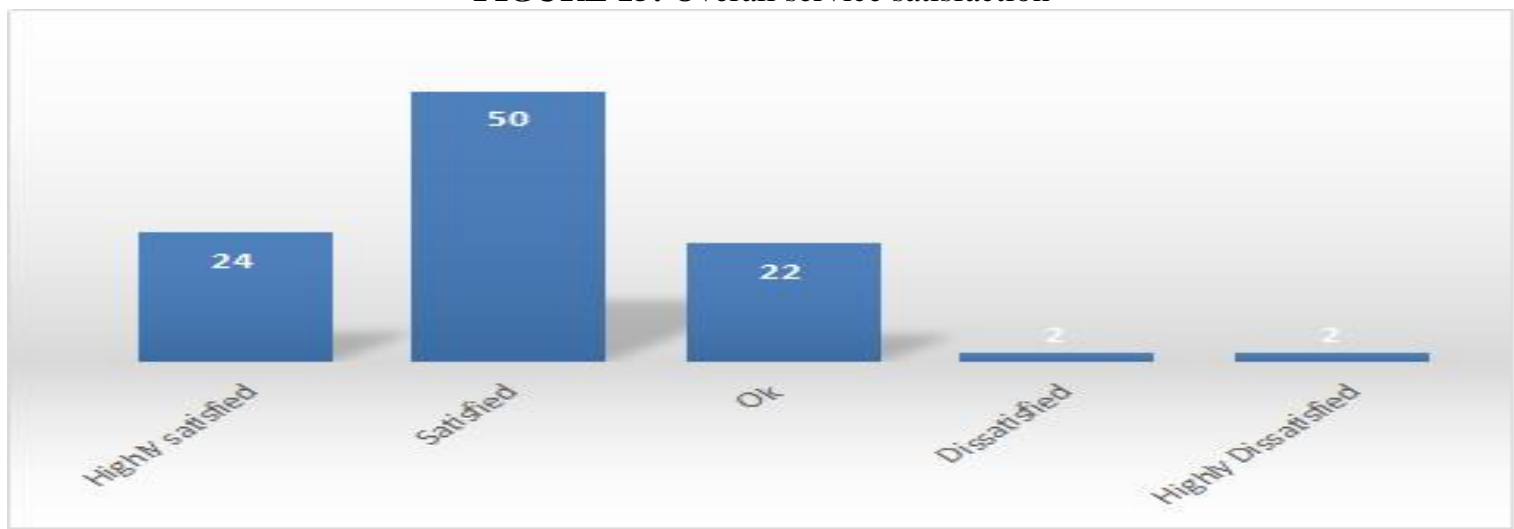

Source: Primary Data 


\section{INTERPRETATION}

$50 \%$ of respondents are satisfied and $24 \%$ are highly satisfied, $22 \%$ are ok with service small portion of $2 \%$ are dissatisfied and only $2 \%$ are highly dissatisfied.

\section{CONCLUSION}

Ours is a society moving on the wheels of technological advancements. Technological changes are also influenced in banking sector. Mobile banking brings a drastic change in the field of banking sector by the implementation of mobile wallets. The study on the topic "A study on customer satisfaction of mobile wallet services provided by Paytm" finds the satisfaction level of users in using various services of Paytm and most satisfied area of Paytm services.

From this study, it is clear that most of the people are aware about the various services of Paytm and they use it in maximum extend. Paytm is drastically used among the youths and increasingly used by students for their transactions. Customers are highly satisfied with the overall services of paytm. Customer services make it unique from other mobile wallets. In this present scenario, mobile wallet service is more beneficial to the society to reduce the cost and time evolved with making the transactions personally by going to their respective banks. After the demonetization of Rs.500 and Rs.1000 notes, Paytm has significantly influenced the society. From the study it is understood that after the demonetization Paytm has taken steps to increases its market share within a short span of time. This would make Paytm one of the most efficient and effective mobile wallet service providers in India.

\section{REFERENCES}

[1] Poonam Painuly \& Shalu Rathi. (2016). Mobile wallet: An upcoming mode of business transactions. International Journal in Management and Social Science, 4, 356- 363.

[2] Jayashree Bose. (2006). E-banking in India: The paradigm shift. ICFAI. Available at: https://catalogue.nla.gov.au/Record/4314140.

[3] Martin M Evans. (2009). Consumer behavior. (2 ${ }^{\text {nd }}$ ed.). John Wiley \& Sons.

[4] 5 things to know about e-wallets. (2017 Nov). India Infoline News Service. Available at: https://www.indiainfoline.com/article/news-personalfinance/5-things-to-know-about-e-wallets117111700473_1.html.

[5] How digital wallets and mobile payments are evolving. (2017 April). Entrepreneur India. Available at: https://www.entrepreneur.com/article/292256.

[6] Growing share of wallet. (2015 Oct). Business Standard. Available at: https://www.businessstandard.com/article/management/growing-share-ofwallet-115101100713_1.html.

[7] Dr. S.Manikandan \& J. Mary Jayakodi. (2017). An emprical study on consumers adoption of mobile wallet with special reference to Chennai city. International Journal of Research - GRANTHAALAYAH, 5(5), 107115. 